\title{
A case of placenta increta in placenta previa: a rare case report
}

\author{
Badal Das*, Debobroto Roy, Malay Sarkar, Krishna Pada Das, \\ Nazmin Khatun, Aritrick Moulick
}

Department of Obstetrics and Gynecology, Burdwan Medical College and Hospital, Burdwan, West Bengal, India

Received: 09 June 2021

Accepted: 05 July 2021

\author{
*Correspondence: \\ Dr. Badal Das, \\ E-mail: drbd.sskm@gmail.com
}

Copyright: (c) the author(s), publisher and licensee Medip Academy. This is an open-access article distributed under the terms of the Creative Commons Attribution Non-Commercial License, which permits unrestricted non-commercial use, distribution, and reproduction in any medium, provided the original work is properly cited.

\begin{abstract}
Placenta increta, one type of morbidly adherent placenta, is characterized by entire or partial absence of the decidua basalis, and by the incomplete development of the fibrinoid or Nitabuch's layer and villi actually invading the myometrium. When the internal os is covered partially or completely by placenta, it is described as a placenta previa. Simultaneously these two complications occurring in a post LSCS scarred uterus is a very rare scenario and anticipated frequently to cause catastrophic obstetric outcome. A 32-years-old woman of second gravida, para 1, with previous history of LSCS 7 years back, with living issue one, admitted in our hospital at 35 weeks 5 days gestation with asymptomatic placenta previa with placenta increta. The case was diagnosed effectively by ultrasonography. Intraoperatively, compression sutures and bilateral uterine artery ligature was tried to control hemorrhage which were failed and a quick decision of caesarean hysterectomy was done. Preserving both ovaries, total hysterectomy was the only option to save the mother in our case. Other options attempting to preserve uterus could have ended up with grave consequences in this case. This was a very rare case of asymptomatic placenta previa with placenta increta in a post LSCS scarred uterus and it was successfully managed by judicious caesarean hysterectomy.
\end{abstract}

Keywords: Caesarean hysterectomy, Decidua basalis, Morbidly-adherent placenta, Myometrium, Nitabuch's layer

\section{INTRODUCTION}

Placenta increta, one type of morbidly adherent placenta, is characterized by entire or partial absence of the decidua basalis, and by the incomplete development of the fibrinoid or Nitabuch's layer and villi actually invading the myometrium. ${ }^{1}$ When the internal os is covered partially or completely by placenta, it is describing a placenta previa. ${ }^{1}$ The incidence of placenta previa is $0.51 \%{ }^{2}$

Placenta increta is considered a rare occurrence with a prevalence of approximately 1 in 2500-7000. It is associated with high morbidity and sometimes with a lethal outcome, mainly as a result of severe bleeding, uterine rupture and infections. ${ }^{3}$ Its incidence is 1 in 700 deliveries. ${ }^{4}$ A study has shown that incidence of placenta acreta spectrum is $0.3 \%$ in women with one previous caesarean section and this incidence is increased to $6.74 \%$ in case of five or more caesarean sections. ${ }^{5}$
Placenta increta is frequently correlated with placenta previa, previous uterine curettage, previous cesarean sections, multiparity (six or more pregnancies), and advanced maternal age. ${ }^{6}$ The precise etiology of this condition remains unclear.

\section{CASE REPORT}

A 32-years-old woman of second gravida, primi para, with a history of lower segment caesarean section with indication of meconium stained liquor 7 years back, and living issue one was admitted in our hospital at 35 weeks 5 days of gestation as she was referred from a subdivisional hospital as a case of placenta previa with increta. She was non-diabetic, non-hypertensive and she had no previous history of any surgical procedure apart from LSCS. She underwent adequate and routine antenatal check up with uneventful antenatal period. Her double marker screening was negative, first trimester ultrasound 
was within normal limit and $2^{\text {nd }}$ trimester anomaly scan at 19 weeks 4 days detected no gross abnormality and the placenta was fundo-anterior in location and far away from internal os. Her third trimester ultrasonography at 35 weeks 5 days revealed placenta anterior low lying and lower pole of placenta covering internal os, placental tissue invading into anterior myometrium, thinned out anterior wall of myometrium in the lower part, loss of normal hypo-echoic retro-placental zone, increased subplacental vascularity (Figure 1) which were suggestive of placenta previa with increta and features of intra-placental hemorrhage was detected and so, she was referred to our tertiary care center for better management.

On admission here, the patient was vitally stable; on abdominal examination: uterus was 36 weeks size, cephalic presentation, in longitudinal lie, head not engaged, fetal heart rate was 146/min and regular. Pervaginal examination was not done; on inspection, there was no vaginal bleeding.

She was given injection dexamethasone $6 \mathrm{mg}$ intramuscularly in 12 hours interval 4 such. An elective caesarean section (class 4) was planned after arranging two units of packed RBC. Patient party was counselled thoroughly regarding the risk of profuse life threatening hemorrhage intra-operatively and the need of caesarean hysterectomy if indicated and a written consent for the same was taken.

Intra-operatively, after giving low transverse incision on the abdomen, thinned out anterior uterine wall with highly vascular placental lake was visible just under the thin uterine serosa as shown in Figure 2.

An incision was given over the uterus approximately $2 \mathrm{~cm}$ above the visible upper margin of the placenta. A part of placenta was needed to cut to deliver the baby. After delivering the baby umbilical cord was clamped and cut immediately (Figure 3).

After extracting placenta, a huge bleeding from placental bed was noted. Bilateral uterine artery was ligated and a transverse B-Lynch (Figure 4) suture was given immediately.

As bleeding was not controlled, the present baby was live and the mother has a previous healthy living issue, we did not waste time attempting bilateral internal iliac artery ligation and a quick decision of hysterectomy was taken. Total caesarean hysterectomy was done preserving both ovaries. After securing hemostasis and matching sutures, mops, gauges and instruments count abdomen was closed in layers. Specimen was sent for histopathogical examination. The post-operative period was uneventful.

Histopathology report, we received after 7 days, revealed the presence of trophoblastic islands and chorionic villi within the thinned-out myometrium and it was diagnosed as placenta increta.
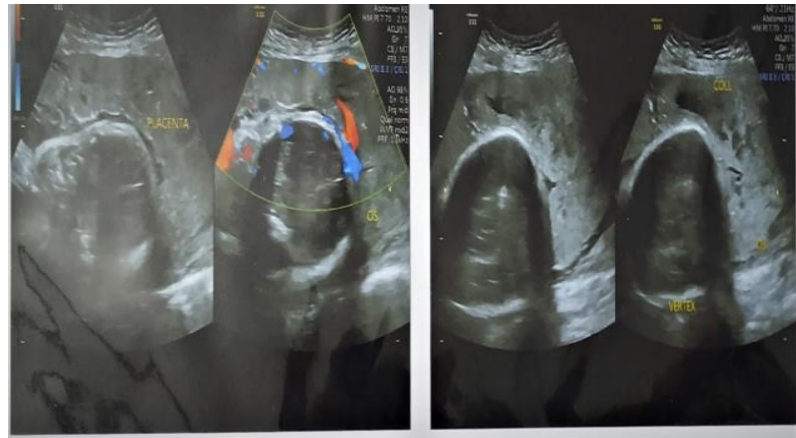

Figure 1: Placenta previa with thinned out anterior myometrium with placental invasion of lower segment, loss of normal hypo-echoic retro-placental zone and increased sub placental vascularity.

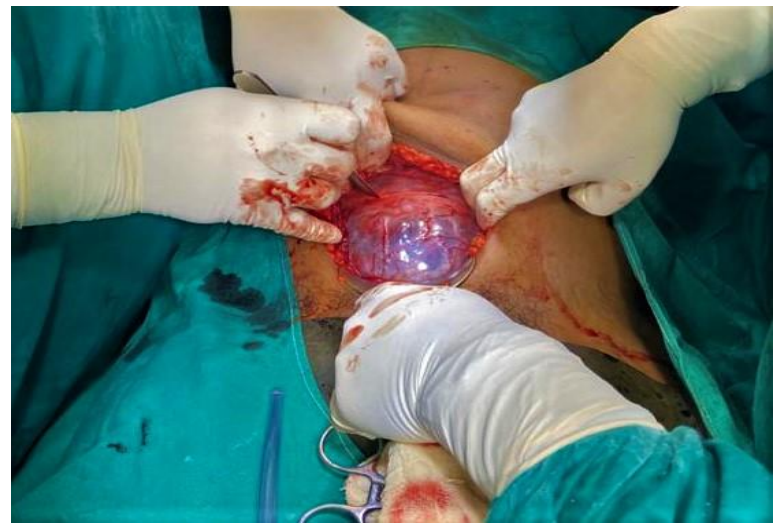

Figure 2: Thinned out anterior myometrium with highly vascular placental lake under the intact thin serosa.

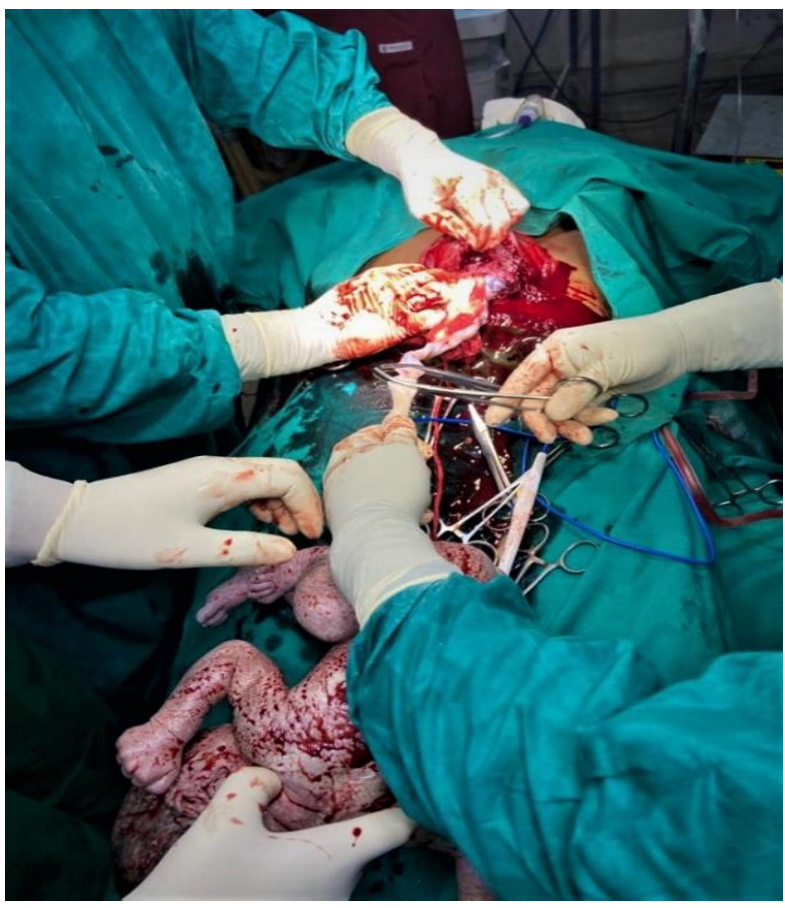

Figure 3: Quick cord clamping after delivery of the baby. 


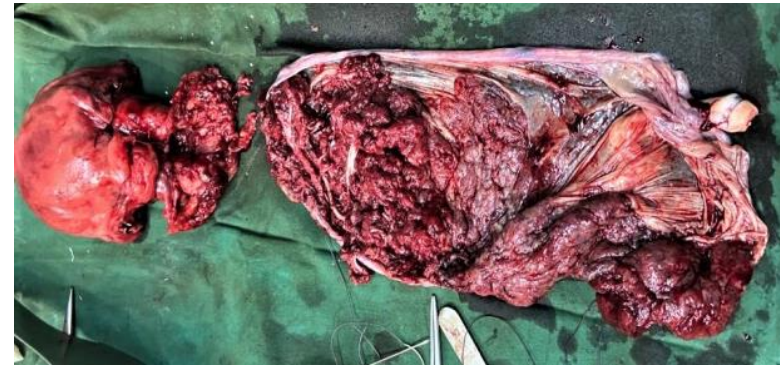

Figure 4: Specimen of uterus showing transverse B-Lynch suture and placenta.

\section{DISCUSSION}

The site of placental implantation, the depth of myometrial invasion, and the width of morbidly adherent placental tissue determines the extent of clinical features of placenta increta, such as hemorrhage, uterine rupture and inversion, and invasion of the urinary bladder. ${ }^{7}$ Myometrial invasion of trophoblastic tissue at the site of a previous cesarean section scar may cause uterine rupture long before the onset of labour. It may even be asymptomatic as seen in our case.

Placenta increta can be diagnosed prenatally by using Doppler ultrasonography and magnetic resonance imaging (MRI). ${ }^{8}$ Although placenta previa is effectively diagnosed by USG, the diagnostic value of ultrasonography in prenatal diagnosis of an asymptomatic placenta increta is uncertain. Finberg et al. reported a positive predictive value of $78 \%$ and a negative predictive value of $94 \% .^{9}$ Other authors suggested that ultrasonography may detect only around $33 \%$ of cases of placenta accreta/increta. ${ }^{10}$ But in our case, though placenta was in fundo-anterior position away from internal os and no sign of placenta increta in second trimester anomaly scan at 19 weeks 4 days, the third trimester ultrasonography was able to diagnose placenta previa and increta so appropriately that we did not need an MRI. This was thought to be happened due to paradoxical placental migration in course of time and we had seen the paramount importance of third trimester ultrasonography.

There was chance of unavoidable painless torrential vaginal bleeding in placenta previa and as it was associated with placenta increta in our case the scenario of torrential vaginal bleeding was not there due to non-separation of placenta. So, there was no question of vaginal delivery in this case as there was placenta previa with increta covering internal os and we decided for elective caesarean section (class 4). A conservative surgery, aiming at uterine rescue by manual removal of as much placental tissue as possible remained an option if there was no living issue or the current one was a dead fetus. Fox et al. reported that $25 \%$ of the women died during this fertility preserving treatment. ${ }^{11}$ Under these circumstances, the conservative treatment can be adopted only in cases of a partial placenta accreta/increta and when bleeding is minimal. Ligature of uterine artery or internal iliac artery, or angiographic embolization can also be tried in these conservative line of management. ${ }^{12}$ But in our case, although initially we tried preserving uterus by compression sutures and bilateral uterine artery ligature, we detected ineffectiveness early and as the family of the mother was completed with the healthy baby of current pregnancy, we did not hesitate in doing caesarean hysterectomy which is the definite and the best option for long-term outcome, as reported previously. ${ }^{13}$ To allow the pregnancy to continue, there have been attempts to treat placenta increta with various drugs including methotrexate, although its safety and the efficacy in this setting are questionable. ${ }^{14-16}$

\section{CONLUSION}

Our patient was a case of ultrasonography diagnosed asymptomatic placenta previa with placenta increta in a scarred uterus, which could be potentially dangerous and life-threatening consequences might occur during delivery, was managed by doing definite treatment, caesarean hysterectomy and the outcome was healthy mother and baby. So, the routine third trimester ultrasonography should always be done in each and every case to rule out this type of placenta previa and acreta spectrum. We presented this case due to its rarity. It is so rare that many obstetricians could have not seen this type of case in their obstetric carrier.

\section{ACKNOWLEDGMENTS}

We are thankful to all of our colleagues, the anesthetist team, OT nursing staffs and OT technicians for their helping hands and immense co-operation.

Funding: No funding sources Conflict of interest: None declared

Ethical approval: Not required

\section{REFERENCES}

1. Cunningham FG, Leveno KJ, Bloom SL, Dashe JS, Hoffmann BL, Casey BM, et al. Williams Obstetrics. 25th ed. New York, NY: McGraw Hill; 2018: 773782.

2. Kumari S, Singh B. Maternal and perinatal outcome of placenta previa in a tertiary care centre: an observational study. Int $\mathbf{J}$ Reprod Contracept Obstet Gynecol. 2018;7:4701-5.

3. Berchuck A, Sokol RJ. Previous cesarean section, placenta increta, and uterine rupture in secondtrimester abortion. Am J Obstet Gynecol. 1983;145:766-7.

4. Mehrabadi A, Hutcheon JA, Liu S, Bartholomew S, Kramer MS, Liston RM, et al. Contribution of placenta accreta to the incidence of postpartum hemorrhage and severe postpartum hemorrhage. Obstet Gynecol. 2015;125(4):814-21.

5. Marshall NE, Fu R, Guise JM. Impact of multiple cesarean deliveries on maternal morbidity: a 
systematic review. Am J Obstet Gynecol. 2011;205(3):262.

6. Miller DA, Chollet JA, Goodwin TM. Clinical risk factors for placenta previa-placenta accreta. Am J Obstet Gynecol. 1997;177:210-4.

7. Haynes DI, Smith JH, Fothergill DJ. A case of placenta increta presenting in the first trimester. J Obstet Gynaecol. 2000;20:434-5.

8. Gielchinsky Y, Rojansky N, Fasouliotis SJ, Ezra Y. Placenta accreta--summary of 10 years: a survey of 310 cases. Placenta. 2002;23(2-3):210-4.

9. Finberg HJ, Williams JW. Placenta accreta: prospective sonographic diagnosis in patients with placenta previa and prior cesarean section. J Ultrasound Med. 1992;11:333-43.

10. Lam G, Kuller J, Mahon M. Use of magnetic resonance imaging and ultrasound in the antenatal diagnosis of placenta accreta. J Soc Gynecol Investig. 2002;9(1):37-40.

11. Fox H. Placenta accreta, 1945-1969. Obstet Gynecol Surv. 1972;27:475.
12. Liu X, Fan G, Jin Z, Yang N, Jiang Y, Gai M, et al. Lower uterine segment pregnancy with placenta increta complicating first trimester induced abortion: diagnosis and conservative management. Chin Med J. 2003;116(5):695-8.

13. Suner S, Jagminas L, Peipert JF, Linakis J. Fatal spontaneous rupture of a gravid uterus: case report and literature review of uterine rupture. J Emerg Med. 1996;14(2):181-5.

14. Crespo R, Lapresta M, Madani B. Conservative treatment of placenta increta with methotrexate. Int $\mathbf{J}$ Gynecol Obstet. 2005;91:162-3.

15. Kayem G, Davy C, Goffinet F, Thomas C, Clement D, Cabrol D. Conservative versus extirpative management in cases of placenta accreta. Obstet Gynecol. 2004;104(3):531-6.

16. Liao CHY, Ding DCH. Failure of conservative treatment for placenta increta. Taiwan J Obstet Gynecol. 2009;48:302-4.

Cite this article as: Das B, Roy D, Sarkar M, Das KP, Khatun N, Moulick A. A case of placenta increta in placenta previa: a rare case report. Int $\mathrm{J}$ Reprod Contracept Obstet Gynecol 2021;10:3245-8. 